\title{
A Miniaturize Bandpass Filter with Harmonic Suppression Using Meandered Quarter-Wavelength Resonators
}

\author{
Yun-Long Lu, ${ }^{1,2}$ Shun Wang, ${ }^{3}$ Tingting Gu, ${ }^{1}$ Ping Cao, ${ }^{1}$ and Kai Li ${ }^{1}$ \\ ${ }^{1}$ Department of Information Science \& Electronic Engineering, Zhejiang University, Hangzhou 310027, China \\ ${ }^{2}$ Hangzhou RFID Research Center, Chinese Academy of Sciences, Hangzhou 310011, China \\ ${ }^{3}$ Institute of Electronics, Chinese Academy of Sciences, Beijing 100190, China \\ Correspondence should be addressed to Shun Wang; swang@mail.ie.ac.cn
}

Received 3 November 2013; Accepted 12 December 2013; Published 18 February 2014

Academic Editor: Said E. El-Khamy

Copyright (C) 2014 Yun-Long Lu et al. This is an open access article distributed under the Creative Commons Attribution License, which permits unrestricted use, distribution, and reproduction in any medium, provided the original work is properly cited.

\begin{abstract}
A miniaturized bandpass filter with harmonics suppression is presented. The proposed filter consists of two quarter-wavelength microstrip resonators, which are meandered for circuit size reduction. An interdigital capacitor, loading at zero-voltage point, is employed to provide the desired coupling between the resonators at operating frequency, whereas the coupling coefficient at the third harmonic is realized to be zero. Besides, the second and fourth harmonics are suppressed since $\lambda / 4$ resonators are adopted. Benefiting from these properties, a miniaturized bandpass filter with the second, third, and fourth harmonics suppression was designed and implemented. The final measured and simulated results show good consistence with the theoretical counterparts.
\end{abstract}

\section{Introduction}

The bandpass filter is one of the most important components in modern RF/microwave systems [1-3]. Unfortunately, without special measures, most of the filters exhibit harmonic responses, which degrade the system performance [4-9]. On the other hand, most mobile devices become smaller and leave limited space for the placement of filters. It is also of importance to miniaturize the required filter size. Therefore, bandpass filters with miniaturized size and harmonics suppression become more and more attractive [1016]. To reduce the circuit size, the designed filters with lower orders are preferred once the passband selectivity and outof-band rejection can reach the design requirements. One important method to improve the selectivity of the filters is to realize transmission zeros at finite frequencies. Moreover, the additional transmission zeros at harmonics can reject unwanted signals without sacrificing the performance of the passband $[17,18]$. Therefore, a low-order filter with the help of transmission zeros may meet the stopband requirement that is usually achieved by higher-order filters. It still has challenges to design a lower order miniature bandpass filter with harmonic suppression. Various structures are proposed in [19-31], such as meandered parallel coupled-line structure [19-26], coupled/slot spur lines [27, 28], fractal-shaped coupled lines [29], and triple-mode stub-loaded resonator $[30,31]$. Recently, a novel coupling schematic is proposed in [32-34] that exhibits one transmission zero at a harmonic frequency. Thus, with this coupling scheme, one more transmission zero is added to the filter, which helps to improve the upper stopband performance. However, most of the filters mentioned above still occupy a fairly large space.

In this letter, a miniature two-order harmonicsuppressed microstrip bandpass filter using meandered quarter-wavelength resonators is presented. An interdigital coupling capacitor is placed on the zero-voltage point of the third harmonic along the resonators. With this benefit, a transmission zero appears at the third harmonic frequency. Besides, two additional transmission zeros located at the lower and upper skirts of the passband are obtained to enhance the selectivity. The circuit size reduction is realized by using two meandered quarter-wavelength resonators. With this structure, the proposed filter not only miniaturizes the circuit size but also extends the rejection band. To verify the performance, the proposed filter is implemented and measured. The active area of the filter is 
TABLE 1: Dimensions of the proposed filter (unit: $\mathrm{mm}$ ).

\begin{tabular}{lcr}
\hline$L_{1}=8.9 \mathrm{~mm}$ & $L_{2}=5.3 \mathrm{~mm}$ & $L_{3}=3.8 \mathrm{~mm}$ \\
$L_{4}=4 \mathrm{~mm}$ & $L_{5}=3 \mathrm{~mm}$ & $L_{6}=3.55 \mathrm{~mm}$ \\
$L_{7}=2.85 \mathrm{~mm}$ & $L_{8}=1.45 \mathrm{~mm}$ & $L_{9}=1.5 \mathrm{~mm}$ \\
$L_{10}=5.4 \mathrm{~mm}$ & $L_{11}=1.2 \mathrm{~mm}$ & $W_{1}=0.5 \mathrm{~mm}$ \\
$W_{2}=1.8 \mathrm{~mm}$ & $g=0.6 \mathrm{~mm}$ & $g_{1}=2.2 \mathrm{~mm}$ \\
$d=0.6 \mathrm{~mm}$ & $L_{i}=1 \mathrm{~mm}$ & $W_{i}=0.2 \mathrm{~mm}$ \\
$g_{i}=0.2 \mathrm{~mm}$ & $g_{2}=1.1 \mathrm{~mm}$ & $s=1.4 \mathrm{~mm}$ \\
\hline
\end{tabular}

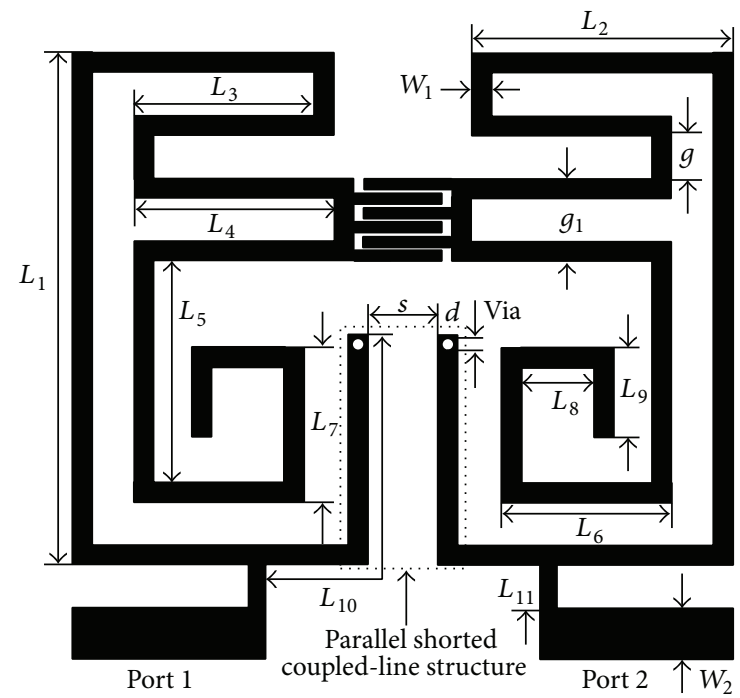

FIgURE 1: Schematic of the proposed miniaturized bandpass filter.

only $8.9 \mathrm{~mm} \times 12.2 \mathrm{~mm}\left(0.052 \lambda_{g} \times 0.071 \lambda_{g} ; \lambda_{g}\right.$ is the guided wavelength at operating frequency), and the rejection band is extended to $4.2 f_{0}$.

\section{Filter Design and Analysis}

Figure 1 depicts the geometrical schematic of the proposed miniature harmonic-suppressed microstrip bandpass filter, which is operating at $f_{0}=1.13 \mathrm{GHz}$. This is a twoorder bandpass filter. The quarter-wavelength resonators are meandered and separated enough, as shown in Figure 1. The substrate in this design is the Rogers 4350 substrate with a relative dielectric constant of 3.48 and a thickness of $0.762 \mathrm{~mm}$. The physical dimensions are shown in Table 1 . The coupling of the proposed bandpass filter is achieved only by the interdigital coupling capacitor, and the coupling coefficient is mainly determined by the location and value of interdigital coupling capacitor. With the meandered quarter-wavelength resonators, the circuit size can be reduced effectively. The input and output ports are connected with the resonators directly. The relation between the external quality and tapper position of input/output port has been investigated in [35].

The interdigital coupling capacitor and its equivalent circuit are shown in Figure 2. $C_{s}$ and $C_{p}$ represent the series and shunt capacitors of interdigital coupling capacitor, respectively [36]. The value of interdigital coupling capacitor

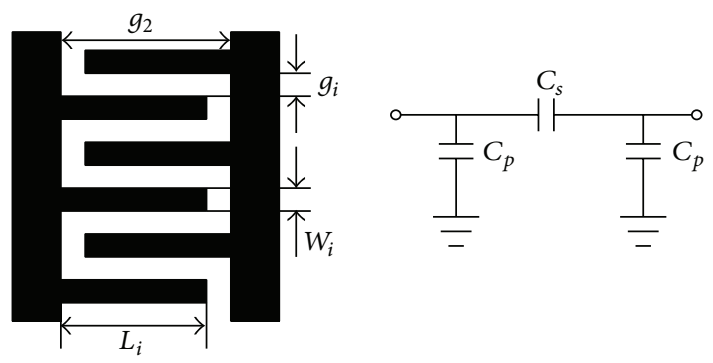

FIGURE 2: Interdigital coupling capacitor and its equivalent circuit.

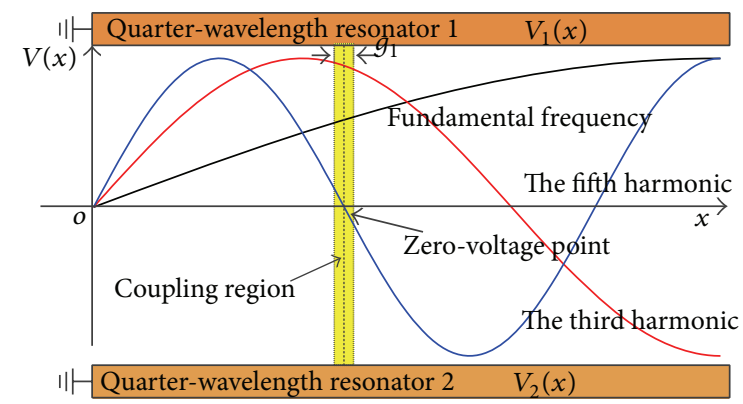

FIGURE 3: Voltage wave functions along the quarter-wavelength resonators.

$C_{\text {int }}$ can be adjusted by changing the parameters $W_{i}, L_{i}$, and $g_{i}$. As the resonators separate away from each other, the coupling between them can be ignored when the interdigital coupling capacitor does not exist. Thus, the coupling is mainly realized by the interdigital capacitor, and the coupling coefficients can be calculated by [37]

$$
|k|=p \times C_{\text {int }} \times\left|v_{1}(x) \times v_{2}(x)\right|,
$$

where $v_{1}(x)$ and $v_{2}(x)$ are normalized voltage wave functions along the two quarter-wavelength resonators and $p$ represents a constant. As we know, the even-mode harmonics cannot be excited at the quarter-wavelength resonators. And thus, only the odd-mode harmonics existed, as shown in Figure 3.

When the center of coupling region is at the zero-voltage point of the third harmonic, $v_{1}(x)$ and $v_{2}(x)$ are nearly to zero for the third harmonic. With the very small length of coupling region $g_{1}$, the coupling coefficient $k$ is close to 0 . As a result, the third harmonic signals cannot pass through the coupling region and thus is suppressed. Therefore, combining the quarter-wavelength resonators and proper position of 

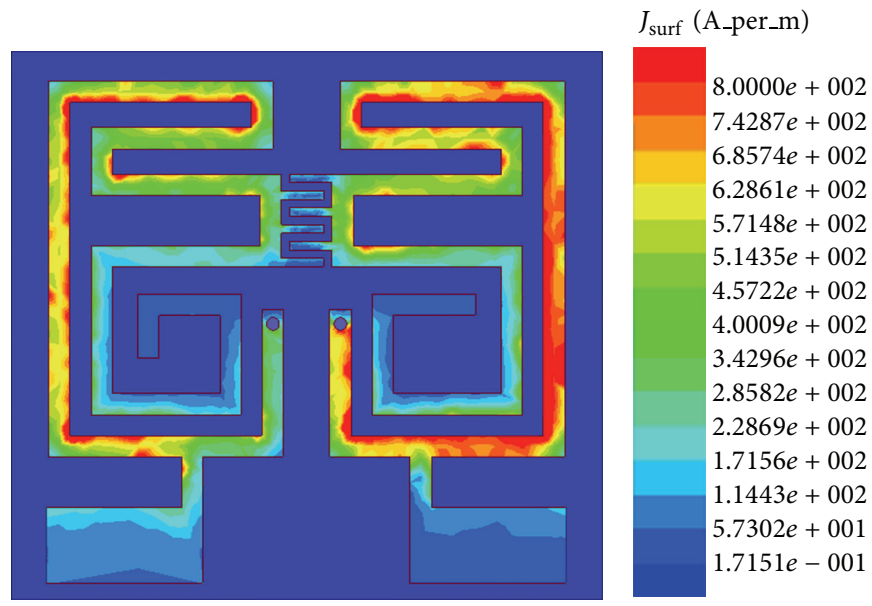

(a)

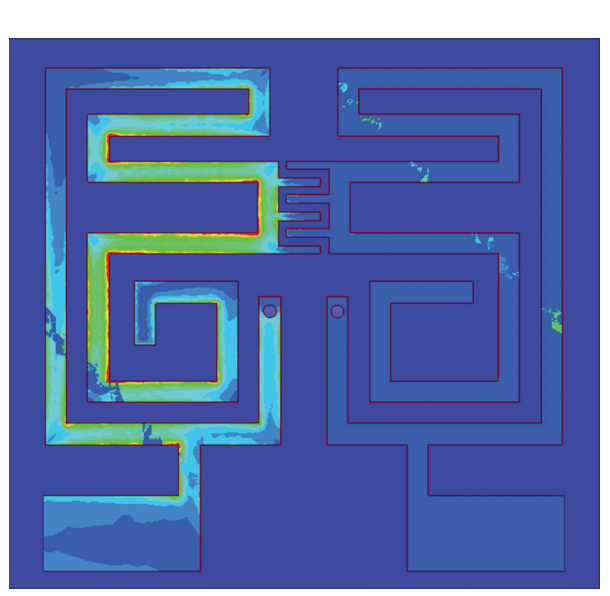

$J_{\text {surf }}$ (A_per_m)

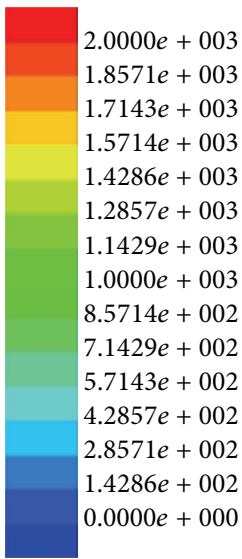

(b)

Figure 4: Current distribution: (a) fundamental frequency and (b) the third harmonic.

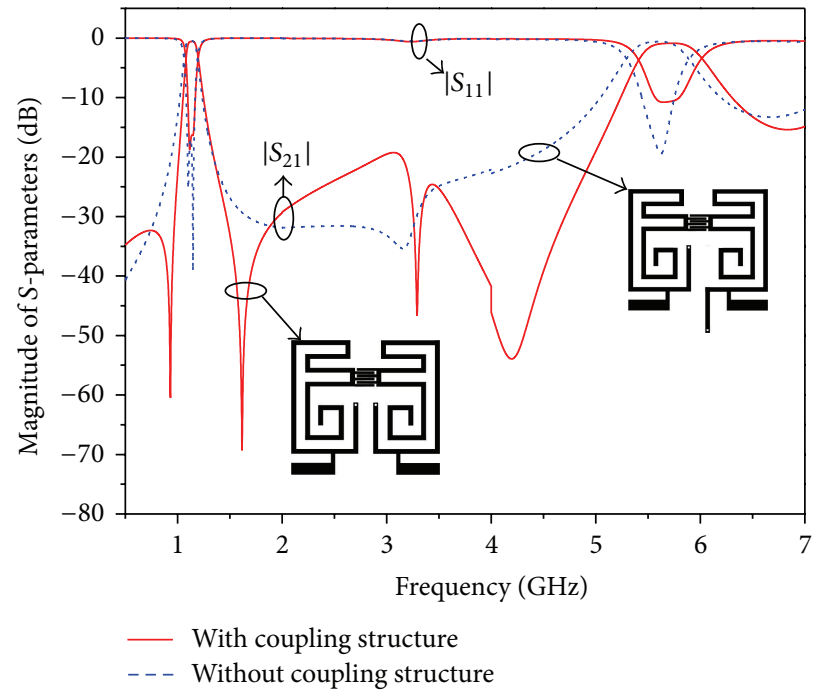

FIGURE 5: Response of proposed bandpass filter of different types. 


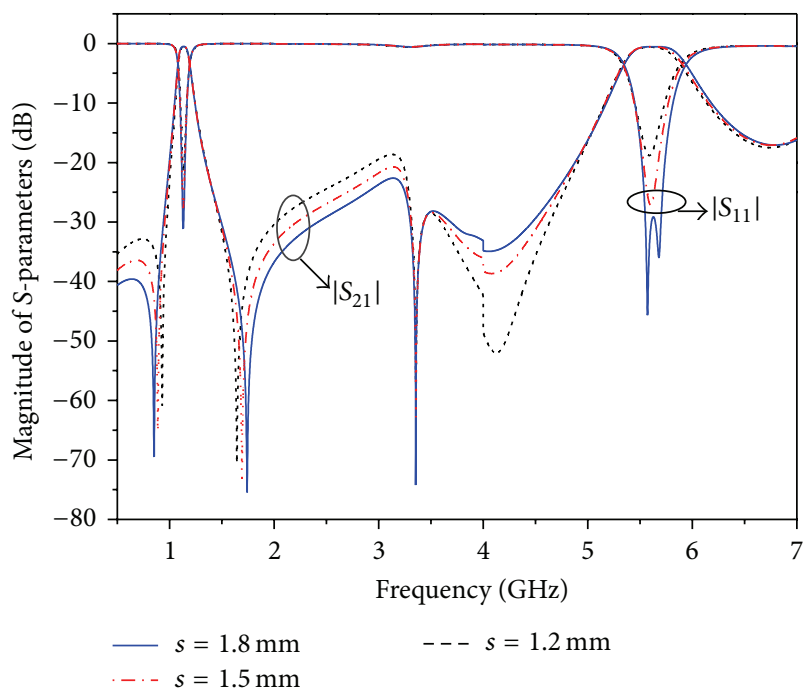

(a)

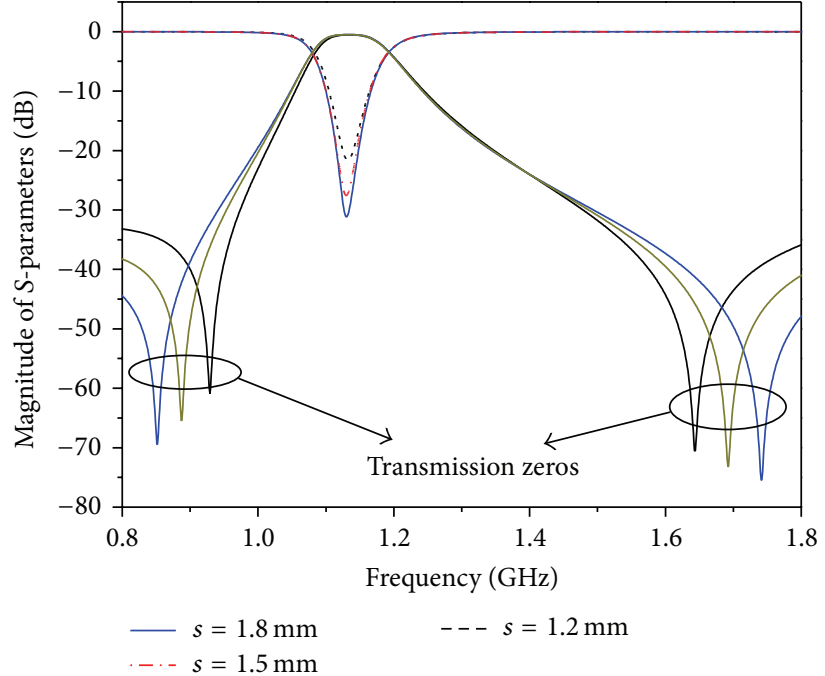

(b)

Figure 6: (a) Transmission characteristics and (b) location of transmission zeros.

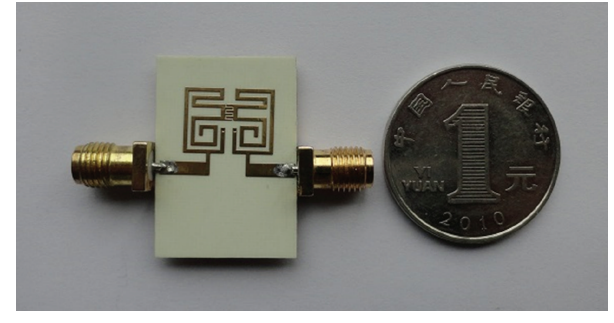

Figure 7: Photograph of the fabricated filter.

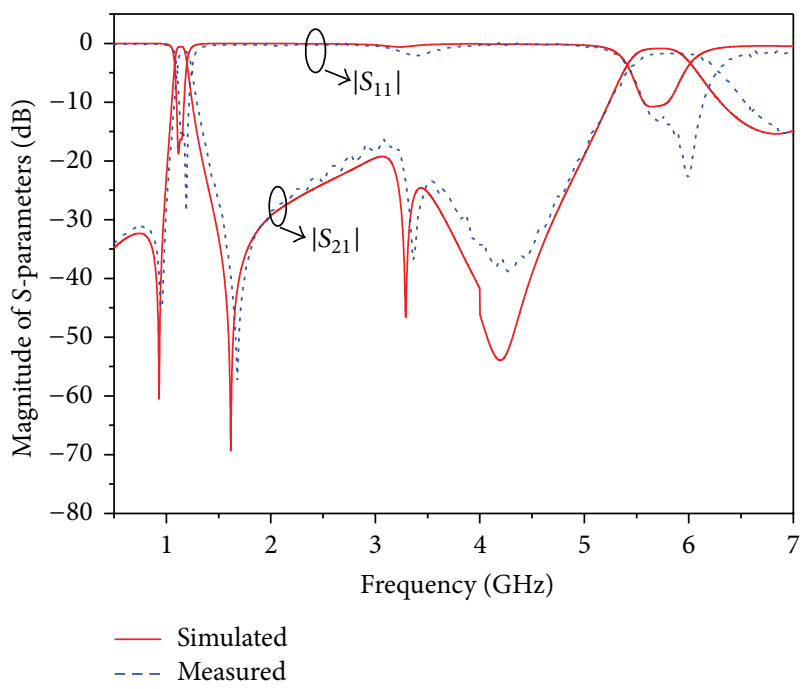

FIGURE 8: Simulated and measured $S$-parameters.

the interdigital coupling capacitor, the rejection band can be extended to the fifth harmonic.

The proposed filter is simulated by the commercially available electromagnetic (EM) simulator of Ansoft HFSS.
Current distributions of the fundamental and third harmonic of the proposed filter are shown in Figure 4. It clearly shows how the fundamental frequency current is coupled from the input port to the output port, whereas the third harmonic is suppressed. This verifies the theoretical analysis stated above.

A parallel shorted coupled-line structure, shown in Figure 1, is adopted to enhance the selectivity. As shown in Figure 5, two additional transmission zeros are realized by the parallel shorted coupled-line structure. This structure is similar to the source-load coupling. Meanwhile, the location of transmission zeros is determined by the gap $s$. The higher selectivity is achieved with the smaller gap $s$, which is shown in Figure 6.

\section{Experiments}

The proposed microstrip bandpass filter is fabricated using printed circuited-board ( $\mathrm{PCB}$ ) process and the photograph is given in Figure 7. The active area of the proposed filter is only $8.9 \mathrm{~mm} \times 12.2 \mathrm{~mm}$, which is about $0.052 \lambda_{g} \times 0.071 \lambda_{g}$, where $\lambda_{g}$ is the guided wavelength at operating frequency. Agilent network analyzer $8358 \mathrm{E}$ is used to test the performance. The simulated and measured results are illustrated in Figure 8 and show good agreements. The centre frequency of the passband is measured at $1.17 \mathrm{GHz}$ against that of the simulated results at $1.13 \mathrm{GHz}$. Furthermore, the measured passband has a $3 \mathrm{~dB}$ bandwidth of $111 \mathrm{MHz}$ or $10.6 \%$. The insertion loss, including the loss from subminiature A (SMA) connectors, is only $1.3 \mathrm{~dB}$ compared to the simulated loss of $0.59 \mathrm{~dB}$. From Figure 8 , it is noted that there are two transmission zeros on the lower and upper skirts of the passband at $0.9 \mathrm{GHz}$ and $1.61 \mathrm{GHz}$. Besides, another transmission zero is located at $3.1 \mathrm{GHz}$. Thus, the third harmonic is efficiently suppressed. It agrees with the theoretical analysis. Therefore, the $20 \mathrm{~dB}$ rejection band is extended to $4.96 \mathrm{GHz}$, which is about $4.2 f_{0}$. 
TABLE 2: Comparison with some previously published designs.

\begin{tabular}{lcccc}
\hline & IL @ $f_{0}$ & $3 \mathrm{~dB}$ FBW & Harmonic suppression* & Size $\left(\lambda_{g}{ }^{2}\right)$ \\
\hline$[26]$ & $2.0 \mathrm{~dB}$ & $26.5 \%$ & $3.9 f_{0}$ & $0.189 * 0.438$ \\
{$[27]$} & $3.3 \mathrm{~dB}$ & $12.5 \%$ & $>3.75 f_{0}$ & $0.166 * 0.141$ \\
{$[28]$} & $1.93 \mathrm{~dB}$ & $4 \%$ & - & $0.175 * 0.175$ \\
{$[29]$} & $2.1 \mathrm{~dB}$ & $5.1 \%$ & $>2 f_{0}$ & $1.03 * 0.171$ \\
{$[30]$} & $1.2 \mathrm{~dB}$ & $13.2 \%$ & $>2 f_{0}$ & $0.21 * 0.15$ \\
{$[31]$} & $0.78 \mathrm{~dB}$ & $15.8 \%$ & $4 f_{0}$ & $0.23 * 0.17$ \\
{$[32]$} & $2.2 \mathrm{~dB}$ & $6.0 \%$ & $2.5 f_{0}$ & $0.557 * 0.124$ \\
This work & $1.3 \mathrm{~dB}$ & $10.6 \%$ & $4.2 f_{0}$ & $0.052 * 0.071$ \\
\hline
\end{tabular}

${ }^{*} 20 \mathrm{~dB}$ rejection bandwidth.

The proposed filter is compared with some previously published designs [26-32] in Table 2. Obviously from the table, the proposed filter has identical or even improved in-band performances. In addition, this work exhibits the smallest circuit size.

\section{Conclusion}

A miniature microstrip bandpass filter with harmonic suppression is presented in this paper. By utilizing the quarterwavelength and position of interdigital coupling capacitor, the second, third, and fourth harmonics are suppressed. The miniaturization characteristic is achieved based on the meandered quarter-wavelength resonator. Compared with the conventional approaches on designing miniature bandpass filter with harmonic suppression, the work in this paper exhibits a smaller circuit size and wider rejection band.

\section{Conflict of Interests}

The authors declare that there is no conflict of interests regarding the publication of this paper.

\section{Authors' Contribution}

Yun-Long Lu contributed with the original idea, simulation, writing, and revising the paper; Shun Wang supplied the test equipment, did the test for the filter, figured out the mistake in the early PCB layout to improve the filter performance, and gave the significant suggestion to revise the paper; Tingting $\mathrm{Gu}$ and Ping Cao assisted the authors to simulate and optimize the proposed filter; Kai Li discussed the design and helped the authors complete the original idea.

\section{Acknowledgments}

This work was partly supported by the National Natural Science Foundation of China (NSFC) under Projects 61201072, 61271086 and the National High Technology Research and Development Program of China (863 Program) under Grant SS2012AA120505.

\section{References}

[1] J. S. Hong and M. J. Lancaster, Microstrip Filters for RF/Microwave Applications, Wiley-Interscience, New York, NY, USA, 2004.

[2] C.-C. Yang and C.-Y. Chang, "Microstrip cascade trisection filter," IEEE Microwave and Wireless Components Letters, vol. 9, no. 7, pp. 271-273, 1999.

[3] A. B. Frazier, R. O. Warrington, and C. Friedrich, "Miniaturization technologies: past, present, and future," IEEE Transactions on Industrial Electronics, vol. 42, no. 5, pp. 423-430, 1995.

[4] S.-G. Mo, Z.-Y. Yu, and L. Zhang, "Compact dual-mode bandpass filters using hexagonal meander loop resonators," Journal of Electromagnetic Waves and Applications, vol. 23, no. 13, pp. 1723-1732, 2009.

[5] J.-T. Kuo and E. Shih, "Microstrip stepped impedance resonator bandpass filter with an extended optimal rejection bandwidth," IEEE Transactions on Microwave Theory and Techniques, vol. 51, no. 5, pp. 1554-1559, 2003.

[6] Y. W. Kong and S. T. Chew, "EBG-based dual mode resonator filter," IEEE Microwave and Wireless Components Letters, vol. 14, no. 3, pp. 124-126, 2004.

[7] L. Zhu and W. Menzel, "Compact microstrip bandpass filter with two transmission zeros using a stub-tapped halfwavelength line resonator," IEEE Microwave and Wireless Components Letters, vol. 13, no. 1, pp. 16-18, 2003.

[8] T. Lopetegi, M. A. G. Laso, J. Hernández et al., "New microstrip "wiggly-line" filters with spurious passband suppression," IEEE Transactions on Microwave Theory and Techniques, vol. 49, no. 9, pp. 1593-1598, 2001.

[9] L.-H. Hsieh and K. Chang, "Piezoelectric transducer tuned bandstop filter," Electronics Letters, vol. 38, no. 17, pp. 970-971, 2002.

[10] H. W. Liu, J. H. Lei, Y. L. Zhao, W. Y. Xu, Y. C. Fan, and T. T. Wu, "Tri-band microstrip bandpass filter using dual-mode steppedimpedance resonator," ETRI Journal, vol. 35, no. 2, pp. 344-347, 2013.

[11] J.-S. Hong and M. J. Lancaster, "Design of highly selective microstrip bandpass filters with a single pair of attenuation poles at finite frequencies," IEEE Transactions on Microwave Theory and Techniques, vol. 48, no. 7, pp. 1098-1107, 2000.

[12] Q.-X. Chu, F.-C. Chen, Z.-H. Tu, and H. Wang, "A novel crossed resonator and its applications to bandpass filters," IEEE Transactions on Microwave Theory and Techniques, vol. 57, no. 7, pp. 1753-1759, 2009. 
[13] S. W. Ren, H. L. Peng, J. F. Mao, and A. M. Gao, "Compact quasielliptic wideband bandpass filter using cross-coupled multiplemode resonator," IEEE Microwave and Wireless Components Letters, vol. 22, pp. 397-399, 2012.

[14] Y. P. Zhang and M. Sun, "Dual-band microstrip bandpass filter using stepped-impedance resonators with new coupling schemes," IEEE Transactions on Microwave Theory and Techniques, vol. 54, no. 10, pp. 3779-3785, 2006.

[15] C.-Y. Chen, C.-Y. Hsu, and H.-R. Chuang, "Design of miniature planar dual-band filter using dual-feeding structures and embedded resonators," IEEE Microwave and Wireless Components Letters, vol. 16, no. 12, pp. 609-611, 2006.

[16] P. K. Singh, S. Basu, and Y.-H. Wang, "Miniature dual-band filter using quarter wavelength stepped impedance resonators," IEEE Microwave and Wireless Components Letters, vol. 18, no. 2, pp. 88-90, 2008.

[17] M. A. El-Tanani and G. M. Rebeiz, "Corrugated microstrip coupled lines for constant absolute bandwidth tunable filters," IEEE Transactions on Microwave Theory and Techniques, vol. 58, no. 4, pp. 956-963, 2010.

[18] S. Sun and L. Zhu, "Periodically nonuniform coupled microstrip-line filters with harmonic suppression using transmission zero reallocation," IEEE Transactions on Microwave Theory and Techniques, vol. 53, no. 5, pp. 18171822, 2005.

[19] L. K. Yeung and K.-L. Wu, "A compact second-order LTCC bandpass filter with two finite transmission zeros," IEEE Transactions on Microwave Theory and Techniques, vol. 51, no. 2, pp. 337-341, 2003.

[20] J.-T. Kuo, C.-Y. Fan, and S.-C. Tang, "Dual-wideband bandpass filters with extended stopband based on coupled-line and coupled three-line resonators," Progress in Electromagnetics Research, vol. 124, pp. 1-15, 2012.

[21] M. Á. Sánchez-Soriano, E. Bronchalo, and G. TorregrosaPenalva, "Parallel-coupled line filter design from an energetic coupling approach," IET Microwaves, Antennas \& Propagation, vol. 5, no. 5, pp. 568-575, 2011.

[22] M. Á. Sánchez-Soriano, G. Torregrosa-Penalva, and E. Bronchalo, "Multispurious suppression in parallelcoupled line filters by means of coupling control," IET Microwaves, Antennas \& Propagation, vol. 6, no. 11, pp. 1269-1276, 2012.

[23] P. Cheong, S.-W. Fok, and K.-W. Tam, "Miniaturized parallel coupled-line bandpass filter with spurious-response suppression," IEEE Transactions on Microwave Theory and Techniques, vol. 53, no. 5, pp. 1810-1815, 2005.

[24] J.-H. Park, S. Lee, and Y. Lee, "Extremely miniaturized bandpass filters based on asymmetric coupled lines with equal reactance," IEEE Transactions on Microwave Theory and Techniques, vol. 60, no. 2, pp. 261-269, 2012.

[25] S.-M. Wang, C.-H. Chi, M.-Y. Hsieh, and C.-Y. Chang, "Miniaturized spurious passband suppression microstrip filter using meandered parallel coupled lines," IEEE Transactions on Microwave Theory and Techniques, vol. 53, no. 2, pp. 747-753, 2005.

[26] Y.-S. Lin and C.-C. Cheng, "Miniature CPW parallel-coupled bandpass filter based on inductive loaded coupled-lines and lumped-element J-inverters," IEEE Microwave and Wireless Components Letters, vol. 17, no. 5, pp. 343-345, 2007.

[27] C.-W. Tang and S.-F. You, "Miniaturised wide stopband rejected microstrip filter with coupled spur-lines," Electronics Letters, vol. 42 , no. 5, pp. 286-288, 2006.
[28] H. Liu, J. Lei, J. Wan, Y. Wang, F. Yang, and S. Peng, "A miniaturized dual-mode bandpass filter using slot spurline technique," International Journal of Antennas and Propagation, vol. 2013, Article ID 853594, 6 pages, 2013.

[29] W.-L. Chen and G.-M. Wang, "Effective design of novel compact fractal-shaped microstrip coupled-line bandpass filters for suppression of the second harmonic," IEEE Microwave and Wireless Components Letters, vol. 19, no. 2, pp. 74-76, 2009.

[30] M. Zhou, X. Tang, and F. Xiao, "Miniature microstrip bandpass filter using resonator-embedded dual-mode resonator based on source-load coupling," IEEE Microwave and Wireless Components Letters, vol. 20, no. 3, pp. 139-141, 2010.

[31] A. Torabi and K. Forooraghi, "Miniature harmonic-suppressed microstrip bandpass filter using a triple-mode stub-loaded resonator and spur lines," IEEE Microwave and Wireless Components Letters, vol. 21, no. 5, pp. 255-257, 2011.

[32] X. Y. Zhang and Q. Xue, "Harmonic-suppressed bandpass filter based on discriminating coupling," IEEE Microwave and Wireless Components Letters, vol. 19, no. 11, pp. 695-697, 2009.

[33] G. le Dai, X. Y. Zhang, C. H. Chan, Q. Xue, and M. Y. Xia, "An investigation of open- and short-ended resonators and their applications to bandpass filters," IEEE Transactions on Microwave Theory and Techniques, vol. 57, no. 9, pp. 2203-2210, 2009.

[34] Y. L. Lu, G. L. Dai, and K. Li, "Dual band bandpass filter using coupled and series capacitors with controllable bandwidths," Microwave and Optical Technology Letters, vol. 55, no. 7, pp. 1543-1546, 2013.

[35] G.-L. Dai and M.-Y. Xia, "An investigation of quarterwavelength square-spiral resonator and its applications to miniaturized bandpass filters," Journal of Electromagnetic Waves and Applications, vol. 24, no. 10, pp. 1303-1313, 2010.

[36] L. Zhu and K. Wu, "Accurate circuit model of interdigital capacitor and its application to design of new quasi-lumped miniaturized filters with suppression of harmonic resonance," IEEE Transactions on Microwave Theory and Techniques, vol. 48, no. 3, pp. 347-356, 2000.

[37] Y. L. Lu and G. L. Dai, "An investigation of novel capacitorbased coupling scheme and its applications to microstrip bandpass filters," Journal of Electromagnetic Waves and Applications, vol. 27, no. 5, pp. 659-669, 2013. 

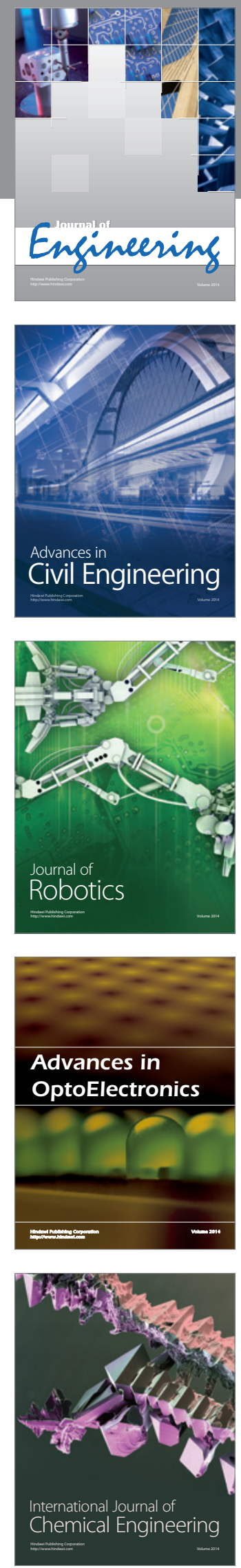

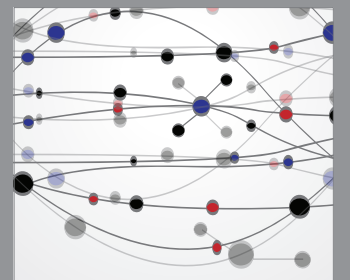

The Scientific World Journal
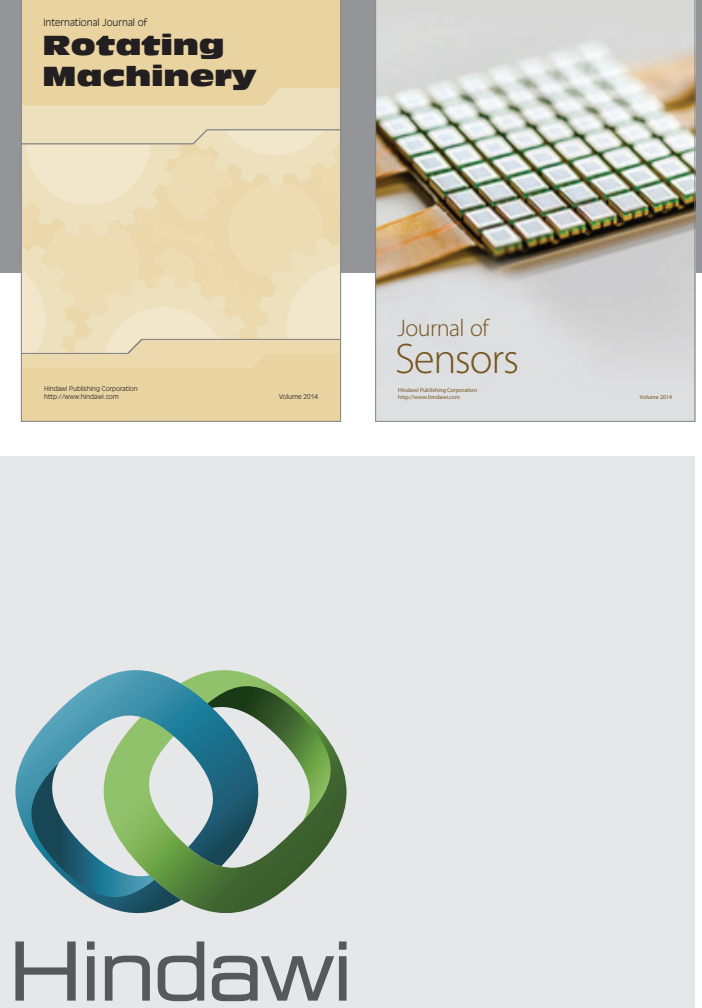

Submit your manuscripts at http://www.hindawi.com
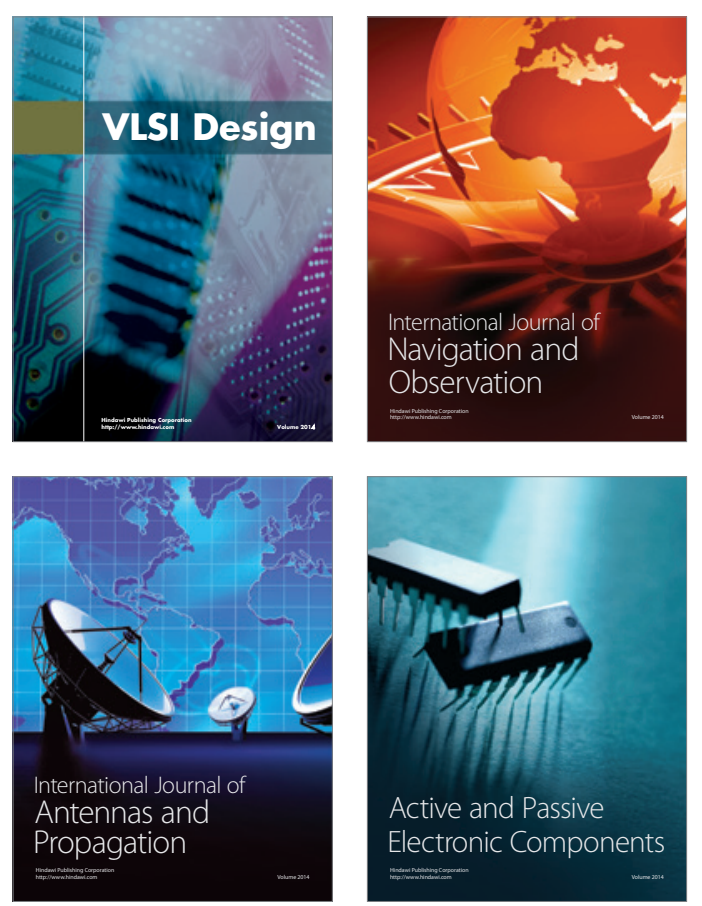
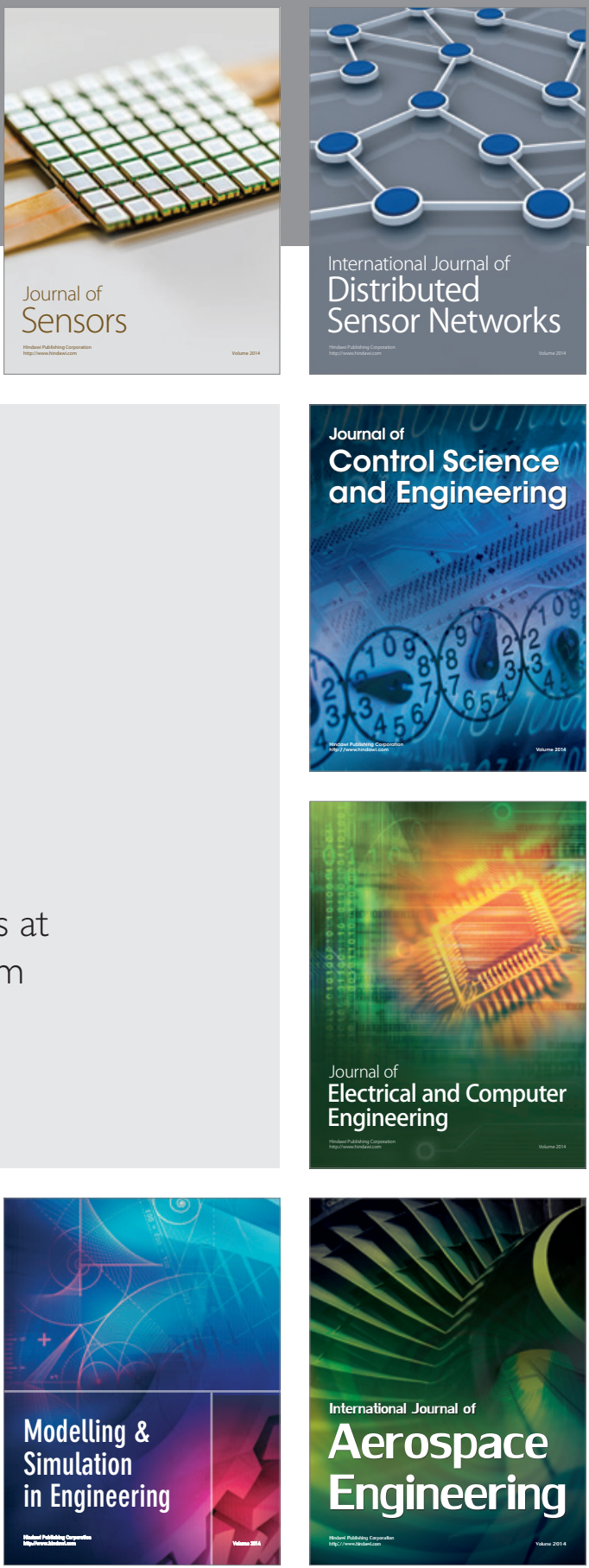

Journal of

Control Science

and Engineering
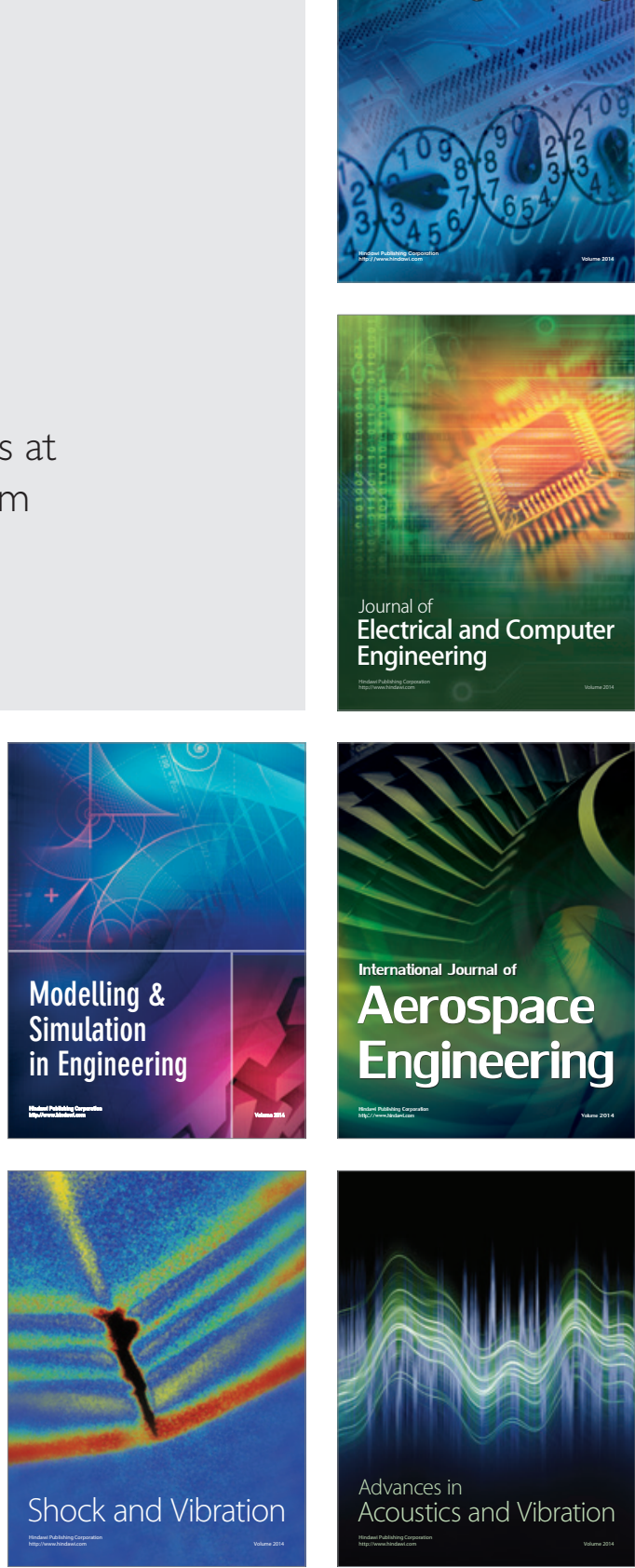